\title{
Debris flow hazard modelling on medium scale: Valtellina di Tirano, Italy
}

\author{
J. Blahut ${ }^{1}$, P. Horton ${ }^{2}$, S. Sterlacchini ${ }^{3}$, and M. Jaboyedoff $f^{2,4}$ \\ ${ }^{1}$ Institute of Rock Structure and Mechanics, Academy of Sciences of the Czech Republic, Prague, Czech Republic \\ ${ }^{2}$ Institute of Geomatics and Risk Analysis, University of Lausanne, Lausanne, Switzerland \\ ${ }^{3}$ Institute for the Dynamic of Environmental Processes, National Research Council (CNR-IDPA), Milan, Italy \\ ${ }^{4}$ Quanterra, Lausanne, Switzerland
}

Received: 13 January 2010 - Revised: 27 June 2010 - Accepted: 28 October 2010 - Published: 25 November 2010

\begin{abstract}
Debris flow hazard modelling at medium (regional) scale has been subject of various studies in recent years. In this study, hazard zonation was carried out, incorporating information about debris flow initiation probability (spatial and temporal), and the delimitation of the potential runout areas. Debris flow hazard zonation was carried out in the area of the Consortium of Mountain Municipalities of Valtellina di Tirano (Central Alps, Italy). The complexity of the phenomenon, the scale of the study, the variability of local conditioning factors, and the lacking data limited the use of process-based models for the runout zone delimitation. Firstly, a map of hazard initiation probabilities was prepared for the study area, based on the available susceptibility zoning information, and the analysis of two sets of aerial photographs for the temporal probability estimation. Afterwards, the hazard initiation map was used as one of the inputs for an empirical GIS-based model (Flow-R), developed at the University of Lausanne (Switzerland). An estimation of the debris flow magnitude was neglected as the main aim of the analysis was to prepare a debris flow hazard map at medium scale. A digital elevation model, with a $10 \mathrm{~m}$ resolution, was used together with landuse, geology and debris flow hazard initiation maps as inputs of the Flow- $\mathrm{R}$ model to restrict potential areas within each hazard initiation probability class to locations where debris flows are most likely to initiate. Afterwards, runout areas were calculated using multiple flow direction and energy based algorithms. Maximum probable runout zones were calibrated using documented past events and aerial photographs. Finally, two debris flow hazard maps were prepared. The first simply delimits five hazard zones,
\end{abstract}

Correspondence to: J. Blahut

(blahut@irsm.cas.cz) while the second incorporates the information about debris flow spreading direction probabilities, showing areas more likely to be affected by future debris flows. Limitations of the modelling arise mainly from the models applied and analysis scale, which are neglecting local controlling factors of debris flow hazard. The presented approach of debris flow hazard analysis, associating automatic detection of the source areas and a simple assessment of the debris flow spreading, provided results for consequent hazard and risk studies. However, for the validation and transferability of the parameters and results to other study areas, more testing is needed.

\section{Introduction}

In landslide studies, hazard is usually defined as the likelihood of occurrence of a potential damaging phenomenon (Crozier and Glade, 2005). From this definition, hazard analysis deals with the occurrence probability evaluation of a damaging phenomenon within a given period of time (Varnes, 1984). The combination of landslide initiation zones, with temporal and spatial probability, and runout zones results in a landslide hazard map (van Westen et al., 2005).

Spatial probability of landslides is the likelihood of the occurrence of a landslide in a given location or terrain unit (Chung and Fabbri, 1999). At medium scale (1:25000-1:50000), within GIS environment, the spatial probability estimation is usually performed within the landslide susceptibility analysis. This requires the comparison of landslides that happened in the past with a set of environmental factors, in order to predict areas of landslide initiation that have similar conditions, using heuristic or statistical methods (van Westen et al., 2005). 
Temporal probability analysis (landslide frequency) could be divided into absolute, relative, and indirect frequency estimation (Corominas and Moya, 2008). Absolute frequency is directly measured and expressed as the number of events per time on an individual slope. Relative frequency is the sum of multiple occurrences and might be expressed as the number of events per area, per time. Indirect frequency can be obtained from indirect evaluation. For debris flows, frequency can be obtained from estimation of accumulated material per time (deposition rate) or from dendrochronological records on trees situated on fans. As already stated by Corominas and Moya (2008), for an analysis at medium scale (1:25000-1:50000), relative frequency is a good descriptor as it assesses multiple occurrences of regional landslide events.

In this study, a map of debris flows susceptibility was used as a basis to calculate probabilities of debris flow initiation. Synthetic values of spatial and temporal probabilities were calculated for each susceptibility class, producing a hazard initiation map. This map was consequently used as the principal input for an empirical GIS-based model (Flow-R), developed at the University of Lausanne, Switzerland. This two-step model delimits potential debris flow sources based on empirical relationships and thematic layers. For landslide hazard analysis, a large amount of data and information is usually needed. However, at medium scale, acquisition of geological factors (such as rock composition, structure, texture, degree of weathering, or bedding/foliation) which affect the debris flow occurrence is very costly and time-consuming (Carrara et al., 1994). The model used in this analysis allowed fast customization and calculation of potential debris flow sources with limited input information. Only DEM was needed to perform the source identification, which was improved by including information about geology, landuse, and the hazard initiation probability.

Consequently, runout zones were modelled. Unlike other models simulating flow over the DEM (e.g. TauDEM; Guinau et al., 2007), Flow-R takes the advantage of multiple flow direction calculation for debris flow spreading. As the aim of this study was to prepare a debris flow hazard map at medium scale, the volume of debris flow was neglected. The maximum probable runout of debris flows (see Sect. 3.5.2) from a particular hazard initiation class was modelled, using aerial photographs and former events for calibration. The presented approach, coupling information about hazard initiation probability and empirical modelling, allowed obtaining prospective debris flow hazard zones with different probabilities of occurrence.

\section{Study area}

The study area (Consortium of Mountain Municipalities of Valtellina di Tirano) is located in the central part of the Valtellina valley (Lombardy Region, Italian Central Alps). It is a consortium of 12 municipalities (Fig. 1), with an

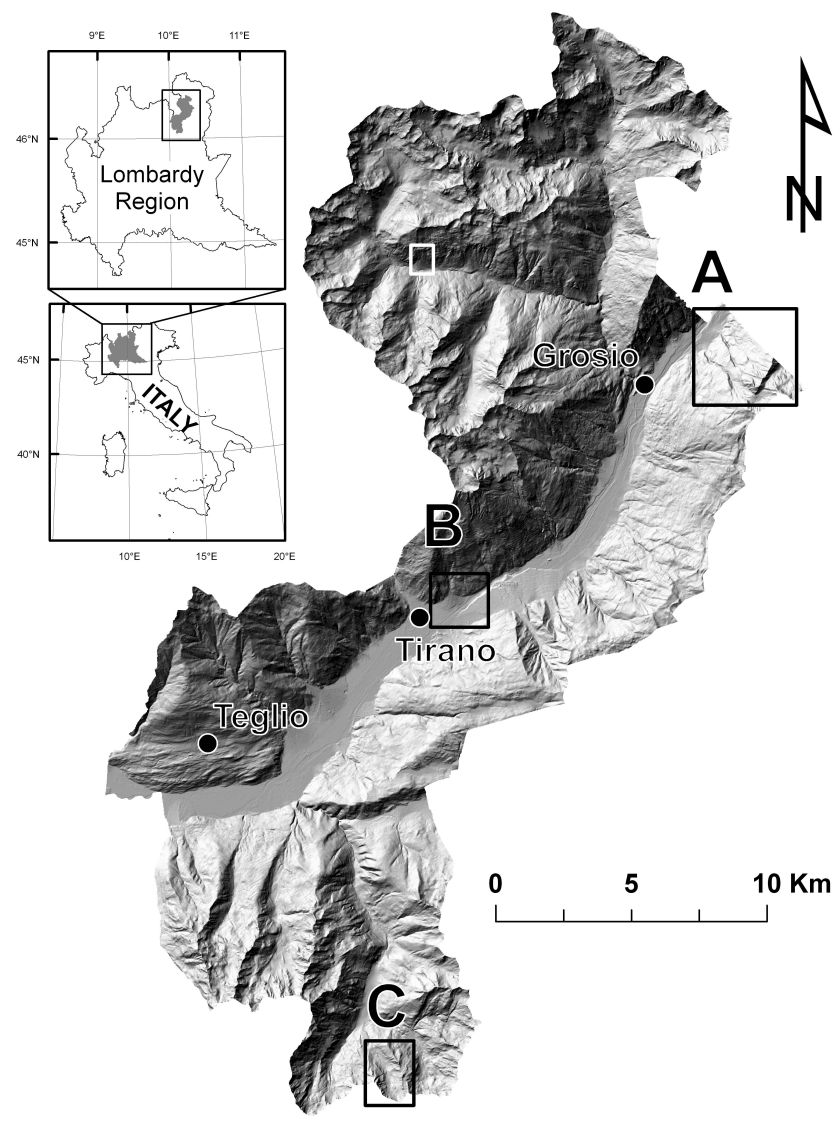

Fig. 1. Hillshade map of the study area. The white rectangle shows the location of Fig. 4, the black rectangles show locations presented on Fig. 7 (A, B, C).

area of about $450 \mathrm{~km}^{2}$ and approximately 29000 inhabitants (prevalently located on the valley floor). The study area has prevalently SW-NE direction resulting from the tectonic setting as it is superimposed on a regional fault (Insubric line). This fault separates the proper Alps (Austroalpine, Penninic and Helvetic nappes) to the north from the Variscan basement of the Southern Alps to the south. The bedrock is mainly composed of metamorphic rocks (gneiss, mica schist, phyllite and quartzite) and intrusive rock units, with subordinate sedimentary rocks. Due to the proximity of the tectonic lineament, cataclastic and mylonitic zones are present. Valtellina has a U-shaped valley profile derived from Quaternary glacial activity. The lower part of the valley flanks are covered with glacial, fluvio-glacial, and colluvial deposits of variable thickness. Alluvial plain of the Adda River is up to $3 \mathrm{~km}$ wide and alluvial fans at the outlet of tributary valleys can reach a considerable size, with a longitudinal length up to $3 \mathrm{~km}$ (Crosta et al., 2003). The elevation of the area ranges from $350 \mathrm{~m}$ a.s.l. at San Giacomo di Teglio, up to $3370 \mathrm{~m}$ a.s.l. at Cima Viola.

Valtellina has a long history of intense and diffused landsliding. The study area suffered from intense rainfall and consequent landslides several times in the past few years. 
The major events occurred in 1983, 1987, 2000, and 2002. Statistical analyses performed by Crosta et al. (1990, 2003) showed that a large percentage of landslides are represented by rainfall-induced, shallow slides and debris flows. Field surveys after the major events mapped mainly shallow soil slips and/or slumps (Crosta et al., 2003) evolving in many times into debris flow affecting the Quaternary cover. These phenomena have an effect on the cultivated areas (one of the most important source of sustenance for people), causing the interruption of transportation corridors and disruptions in inhabited areas, sometimes leading to the temporary evacuation of people.

Two main types of debris flows can be recognized in the area: soil slips-debris flows on vineyard terraces and debris flows that were triggered in natural conditions which are more frequent in the higher parts of the valley, originating mostly in 0th or 1st order basins as shallow landslides and evolving into debris flows (Crosta et al., 1990). These debris flows can reach the valley bottom and cause considerable damage as it did in Tiolo (Grosio municipality) in 1987.

In this study only the debris flows that are triggered in natural conditions are considered because the current maintenance state of the vineyard terraces (which affects the soil slip-debris flow initiation) is not mapped and available for performing a reliable hazard analysis.

\section{Materials and methods}

\subsection{Data}

To prepare the debris flow hazard map, the following data were used:

- Debris flow susceptibility map that was calculated exploiting the Weights-of-Evidence modelling technique (Blahut et al., 2010) and that was classified into five susceptibility classes.

- Two sets of aerial photographs from 2001 (IT2000) and 1981 (TEM1), that were used to prepare two debris flow inventories.

- A $10 \mathrm{~m}$ resolution digital elevation model (DEM), which was obtained generalizing a 5 meter DEM prepared in 2001 using photogrammetry techniques. The resolution was decreased in order to have similar resolution of all inputs, which is very important as the final resolution of the model is similar to the resolution of the worst input. This approach also leads to reduction of the computation time.

- Landuse map, which was derived from the 1:10000 scale map of the DUSAF project (2003), prepared by the Lombardy Region using orthophotos of the year 2001. The land use map is classified in 23 classes, of which the largest ones are coniferous forests and bare land (scarce vegetation).

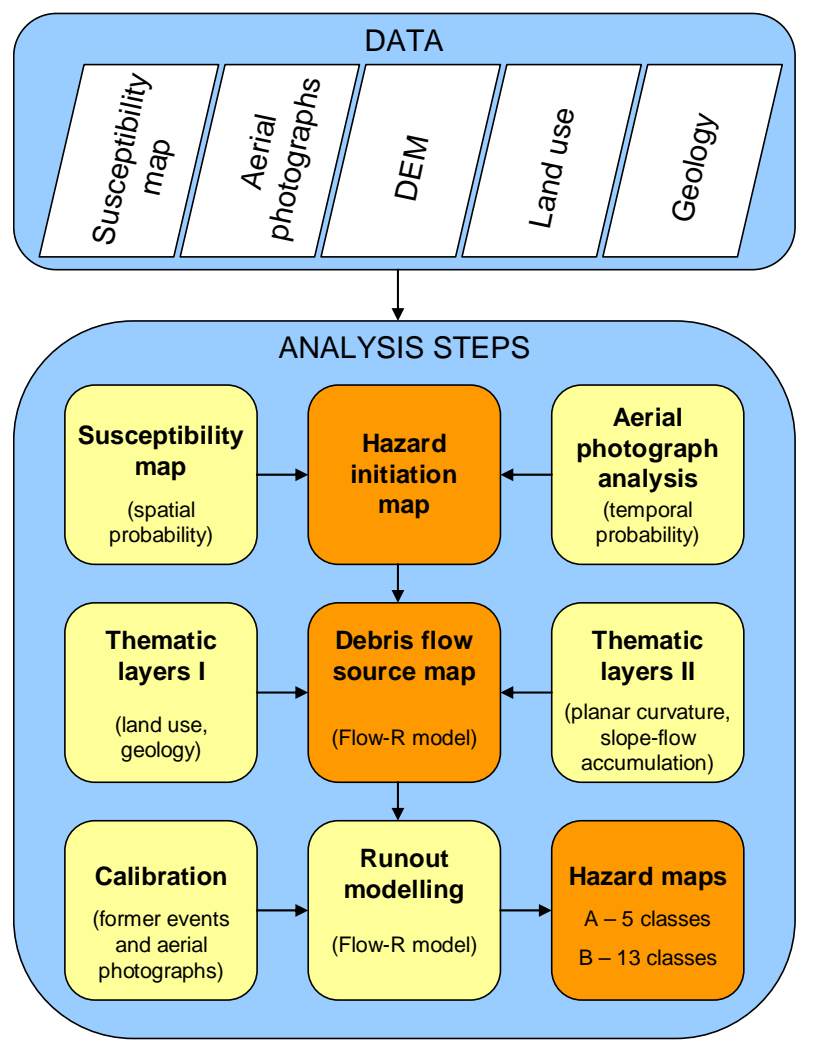

Fig. 2. Flowchart of the applied analysis method. Light boxes show modelling inputs and the dark boxes show intermediate and final results.

- Geological map, which was rasterized from the 1:10000 scale geological map of the Lombardy Region (CARG project, 1992). The map contains 51 lithological units that were mapped in the field and by photo interpretation. Morainic deposits and gneiss rocks represent the most frequent classes.

\subsection{Principal methodological steps}

Flowchart of the analysis is presented on Fig. 2. Firstly, all data needed were gathered and rasterized in $10 \mathrm{~m}$ resolution in order to have similar inputs for the analysis. The available susceptibility map was used as a basis for hazard initiation calculations. For each susceptibility class a spatial probability was calculated in terms of the density of debris flow scarps in each susceptibility class (see Sect. 3.3). Then, temporal probability was estimated for each of the susceptibility classes based on the comparison of two sets of aerial photographs (see Sect. 3.4). This calculation resulted in the hazard initiation probability map for the entire study area. This map served as the main input for the consequent modelling using Flow-R. The hazard initiation map classifies the study area into five homogenous zones. However, these zones contain locations 
where debris flow triggering is impossible due to the low flow accumulation, low slope, etc. Thus, the potential debris flow sources were selected/identified using available statistical information about debris flow scarp distribution in land use and geology classes and empirical information delimiting the gullies (planar curvature map) and upslope contributing area (slope-flow accumulation relationship; see Sect. 3.5.1). Subsequently, the runout modelling was performed using available historical events and aerial photographs for calibration. Therefore, a 5-class debris flow hazard map was obtained, delimiting the probabilities of occurrence. The last step involved reclassification of the 5-class map into 13 classes (three subclasses for very high, high, medium and low occurrence probabilities) in order to delimit areas of higher/lower probabilities of debris flow spreading. As a result, two hazard maps were prepared for the study area.

\subsection{Spatial probability of initiation}

The debris flow susceptibility map was calculated using a bivariate statistical technique (Weights-of-Evidence; Blahut et al., 2010). The results from the susceptibility analysis using the Weights-of-Evidence technique assign a single value of spatial probability to each analysed cell. The map was classified into five classes (very high, high, medium, low, and very low) using success rate curves (Chung and Fabbri, 1999). Susceptibility class limits were selected at $75 \%$, $85 \%, 95 \%$; and $99 \%$ of debris flow scarps from the DF2001 inventory, falling in each susceptibility class.

As the results from the classification can not give a single value of the spatial probability for the entire susceptibility class, spatial probability of debris flow scarp occurrence in each susceptibility class was calculated using the following equation:

$P_{\mathrm{S}}=\frac{N_{\text {DFpixScls }}}{N_{\text {pixScls }}}$

where: $P_{\mathrm{S}}=$ spatial probability of debris flow occurrence; $N_{\text {DFpixScls }}=$ number of debris flow scarp pixels in each susceptibility class; $N_{\text {pixscls }}=$ number of pixels of the particular susceptibility class.

The assumption of calculation of one single value of spatial probability per class was necessary because the available classified susceptibility map was used as the principal input for the analysis. Some limitations may arise from this approach. However, considering the scale of the analysis and potential applicability to other study areas it was decided to make this assumption. For more information about the susceptibility map preparation, please refer to Blahut et al. (2010).

\subsection{Temporal probability estimation}

In relative temporal probability analysis, the frequency is assessed as the number of landslides per unit area (expressed in number of pixels or $\mathrm{km}^{2}$ ) per year (Corominas and Moya, 2008). In this study, the temporal probability of debris flow occurrence was assumed to be equal to the area of new debris flow scarps in each susceptibility class per year.

To perform this analysis, we compared two debris flow inventories that were prepared using two sets of aerial photographs The former inventory (abbreviated DF1981) was prepared analysing the aerial photographs taken in 1981 (flight TEM1); this was compared with the latter inventory (abbreviated DF2001), prepared exploiting the 2001 aerial photographs (flight IT2000). Only the scarp areas where debris flow activity was observed between these two periods were taken into account for the temporal probability calculation.

Debris flow scarps where new activity was observed during the 20-year-period were overlapped (compared with) the five classes of the susceptibility map, obtaining the temporal probability of debris flow occurrence in each susceptibility class:

$$
P_{\mathrm{T}}=\frac{\frac{N_{\text {NEWDFpixScls }}}{N_{\text {pixScls }}}}{T}
$$

where: $P_{T}=$ temporal probability of debris flow occurrence; $N_{\text {NEWDFpixScls }}=$ area of new debris flow scarps (in pixels) in each susceptibility class which appeared within a time period; $N_{\text {PixScls }}=$ area (in pixels) of the corresponding susceptibility class; $T=$ time period.

The hazard initiation probability map of debris flows was computed combining the information from the susceptibility map and spatial and temporal probability, using the following equation:

$P_{\mathrm{HI}}=P_{\mathrm{S}} \cdot P_{\mathrm{T}}$

where: $P_{\mathrm{HI}}=$ hazard initiation probability of debris flow; $P_{\mathrm{S}}=$ spatial probability of occurrence; $P_{\mathrm{T}}=$ temporal probability of occurrence.

As a result, a single value of spatial, temporal, and initiation probability was assigned to each susceptibility class resulting in a five-class hazard initiation map.

\subsection{Flow-R modelling}

In most debris flow hazard studies at medium scale, the runout modelling still remains as the principal problem. In this study, a regional debris flow runout model (Flow-R), was used. Because the model was described in detail by Horton et al. (2008), only a brief explanation is given here.

The model is subdivided into two main parts: (1) identification of debris flow sources, and (2) modelling of debris flow runout. Both the sources identification and the runout modelling can be performed on a regular DEM with a resolution of 10 or $20 \mathrm{~m}$. In this study a DEM with a resolution of $10 \mathrm{~m}$ was used. 


\subsubsection{Identification of sources}

Results from the hazard initiation map (Sect. 3.4) can provide reliable results in classifying areas with different probabilities of debris flow initiation. However, this output itself can not serve as the only input for the Flow-R model, because the model will consider some areas as possible debris flow sources even if they do not fulfil the essential conditions for debris flow initiation (minimum slope, minimum flow accumulation, etc.). This situation is a result of classifying the whole study area into different hazard initiation classes. For that purposes, the hazard initiation areas had to be restricted to cells where the conditions agree with the empirical observations.

According to Rickenmann and Zimmermann (1993) and Takahashi (1981), three geo-environmental factors in a critical combination are relevant for debris flow initiation: slope gradient, water input, and sediment availability. In our analysis, we combined several information layers in order to fulfil the three above mentioned main factors for the detection of potential debris flow sources:

- DEM and derived morphometric maps (slope, flow accumulation and planar curvature maps).

- Geological map.

- Land use map.

For each map, a grid was generated containing three possible values for each cell: possible source - excluded cell ignored cell. Combining the grids prepared from different maps, a cell was selected as a source area if it was identified as a possible source at least once, but never was classified as excluded. Ignored cells were not taken into account in the analysis as all possible sources were considered.

The slope angle is a major factor, which determines the triggering of a debris flow (Takahashi, 1981). Most debris flows occur in areas with a slope higher than $15^{\circ}$ (Rickenmann and Zimmermann, 1993; Takahashi, 1981). As a consequence, all cells with a slope angle larger than $15^{\circ}$ were considered as possible sources and those below this threshold were excluded from the analysis.

The upslope contributing area was taken into account as a characteristic of water input; a minimum contributing area of 1 hectare was defined. The initiation threshold of slope angle and contributing area was expressed by an empirical equation based on observations of Rickenmann and Zimmermann (1993) and Heinimann (1998; Fig. 3). For this study, an "extreme fitting" curve was selected, as it covers a higher possibility for debris flow initiation. All cells below this threshold were excluded from possible sources as it is not probable that debris flows will initiate under the proposed line, according to empirical observations.

The planar curvature map (detection of gullies), geology and the landuse map were added to increase the detection quality of debris flow source areas. In the planar curvature

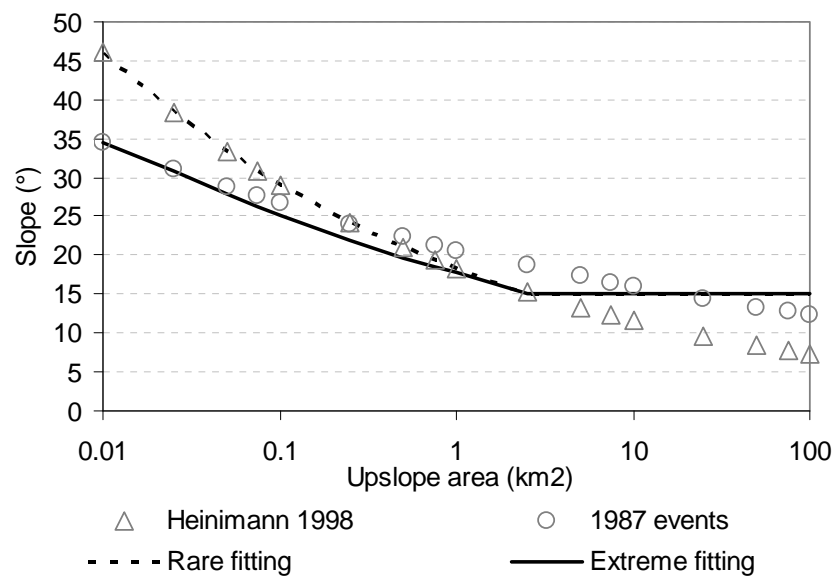

Fig. 3. Curves showing the initiation threshold of debris flows considering the slope angle and the upslope contributing area (flow accumulation). In the analysis the extreme fitting curve was used (after Horton et al., 2008).

map, only cells with a curvature lower than $-2 / 100 \mathrm{~m}^{-1}$ on a $10 \mathrm{~m}$ DEM were considered as possible sources. This observation fits best for the occurrence of debris flow initiation areas in Alpine regions, such as the Swiss Alps (Horton et al., 2008) and Valtellina.

The sediment availability was evaluated using the geological data, as some geological units produce higher or lower amount of debris according to their weathering characteristics. The geological units prone to debris flow initiation were selected based on an empirical analysis, considering that debris flow prone areas are only in those geological units where debris flows occurred in the past. The former debris flow activity was analysed from the available inventories. It has to be stressed that in cases when a debris flow removes all available sediments on a slope, the hazard decreases from high to low, because no material is available for a debris flow mobilisation. In such cases, areas where debris flow occurred in the past are less hazardous than those without past debris flow occurrence. However, due to the scale of this study, this possibility was neglected.

From the 51 geological units present in the study area, 17 were excluded as they have not experienced debris flow initiation according to the available inventories (e.g. alluvial sediments, dolomite, quartzite, or peat).

The landuse map classes were selected in the same way as geological classes, considering only those which experienced debris flow initiation in the past. From the 23 land use classes, 15 were excluded from the analysis as they have not experienced debris flow initiation in the past (e.g. urbanized areas, water, quarries, or orchards). Cells from the planar curvature, geology and land use maps were excluded for cases, when abovementioned criteria was not met.

Ultimately, the hazard initiation probability map was also incorporated to the detection of sources to include initiation probabilities. The four highest hazard initiation classes 
were used to obtain different debris flow source maps, with different probabilities of initiation. This approach led to the calculation of a four-class debris flow source map which was subsequently used as an input in the runout calculation. The lowest hazard initiation class was excluded from the source identification as it represents the very low-residual hazard covering the rest of the study area.

\subsubsection{Runout and spreading modelling}

The debris flow runout and spreading can be mathematically estimated by two types of algorithms: the algorithms which compute the path of the debris flow and algorithms that determine the runout distance (Horton et al., 2008).

The runout and spreading assessment started from computing the path of potential debris flow from each potential source area, identifying the flow direction (in probabilistic terms), and then calculating the runout distances. The DEM was the only data needed to perform the calculation of the runout.

Flow direction algorithms control the direction of the flow from one cell to its eight neighbours. For our purposes, a multiple flow direction algorithm, firstly introduced by Quinn et al. (1991), was applied after performing a calibration targeted to evaluate the best-fitting model and to find the best correspondence among past event and aerial photographs with computed results. Concerning the angle of spreading, Holmgren (1994) introduced an exponent in the algorithm which controls the convergence of the flow (the higher is the exponent, the more convergent the flow becomes). According to Claessens et al. (2005) and Horton et al. (2008), the optimal values of Holmgren exponent for debris flow spreading are between 4 and 6 (Eq. 4).

$$
f_{\mathrm{s} i}=\frac{\left(\tan \beta_{i}\right)^{x}}{\sum_{j=1}^{8}\left(\tan \beta_{i}\right)^{x}}
$$

where $i, j=$ flow directions $(1 \ldots 8), f_{\mathrm{s} i}=$ flow proportion $(0 \ldots 1)$ in direction $i, \tan \beta_{i}=$ slope gradient between the central cell and the cell in direction $i$, and $x=$ variable exponent.

A weighting of the directions is included to take into account the persistence of the debris flow, representing its inertia. Based on Gamma (2000), the weight is a function of the change in angle from the last flow direction:

$$
\left\{\begin{array}{l}
f_{\mathrm{p} i}=w_{0} \quad \Leftrightarrow a_{i}=0^{\circ} \\
f_{\mathrm{p} i}=w_{45} \Leftrightarrow a_{i}=45^{\circ} \\
f_{\mathrm{p} i}=w_{90} \Leftrightarrow a_{i}=90^{\circ} \\
f_{\mathrm{p} i}=w_{135} \Leftrightarrow a_{i}=135^{\circ} \\
f_{\mathrm{p} i}=0 \Leftrightarrow a_{i}=180^{\circ}
\end{array}\right.
$$

where $i=$ flow directions $(1 \ldots 8), f_{\mathrm{p} i}=$ flow proportion $(0 \ldots 1)$ in direction $i, \alpha_{i}=$ angle between the previous direction and the direction from the central cell to cell $i, w_{0,45,90,135}=$ weights for the corresponding change in direction.

Resulting probabilities are a combination of the multiple flow direction algorithm and persistence:

$$
f_{i}=\frac{f_{\mathrm{s} i} \cdot f_{\mathrm{p} i}}{\sum_{j=1}^{8} f_{\mathrm{s} j} \cdot f_{\mathrm{p} j}} \cdot f_{0}
$$

where $i, j=$ flow directions $(1 \ldots 8), f_{i}=$ total flow proportion $(0 \ldots 1)$ in direction $i, f_{\mathrm{si}}=$ flow proportion from the sloperelated algorithm, $f_{\mathrm{p} i}=$ flow proportion from the persistence, $f_{0}=$ previously determined flow proportion of the central cell.

This calculation (Eq. 6) allows including each cell having a minimal probability of being in debris flow path. Thus, for the spreading assessment of a source cell, the calculation integrates different paths or divergences in one run. There is no need of random multiple runs as the field of all probabilities is covered (Horton et al., 2008).

The outputs from the modelling are expressed in terms of probabilities calculated as functions of slope and persistence, which is a weighting of the directions according to the previous direction. This allows an integration of the notion of inertia (Horton et al., 2008). On alluvial and debris fans, debris flows tend to change direction easily, after leaving the principal erosion gully, which regulates the flow on steeper parts of the terrain. On lower slope gradients, the change of the flow direction is represented by a probability function. However, this function is not a mathematical probability in a strict sense and resulting probabilities have to be interpreted in a qualitative way (Huggel et al., 2003).

Runout distance algorithms are basic energy-based calculations that define whether a part of the debris flow can potentially reach another cell. Thus, they control the distance reached by the debris flow and, in addition, reduce the divergence. In that way, the energy-based algorithms also influence the flow direction, as each cell that cannot be reached has a probability set to zero. In a regional runout model, the source mass is unknown. Thus, runout distance calculation is based on a unit energy balance (7), a constant loss function and a maximum threshold. This approach does not aim to represent the physical processes exactly, but to result in realistic outcome:

$E_{\mathrm{kin}}^{i}=E_{\mathrm{kin}}^{i-1}+\Delta E_{\mathrm{pot}}^{i}-E_{\mathrm{loss}}^{i}$

where $i=$ time step, $E_{\text {kin }}=$ kinetic energy, $\Delta E_{\text {pot }}=$ change in potential energy and $E_{\text {loss }}=$ constant loss.

The probable maximum runout is characterized by an average slope angle (Huggel et al., 2002) or shadow angle (Michael-Leiba et al., 2003) which is the average slope between the starting and end points, following the debris flow path. A constant friction loss has been considered, corresponding to this angle, which would result in a runout 
Table 1. Calculated probability values of the debris flow hazard initiation map. VH: very high, H: high, M: medium, L: low, VL: very low.

\begin{tabular}{lrrcccc}
\hline $\begin{array}{l}\text { Hazard } \\
\text { initiation } \\
\text { class }\end{array}$ & Area & $\begin{array}{r}\text { Area } \\
\text { in } \%\end{array}$ & $\begin{array}{c}\text { New debris } \\
\text { flow pixels }\end{array}$ & $\begin{array}{c}\text { Spatial } \\
\text { probability }\end{array}$ & $\begin{array}{c}\text { Temporal } \\
\text { probability } \\
\times 10^{-2}\end{array}$ & $\begin{array}{c}\text { Initiation } \\
\text { probability } \\
\times 10^{-4}\end{array}$ \\
\hline VH & 655676 & 14.52 & 5814 & 0.0507 & 0.0443 & 0.224783 \\
H & 299317 & 6.63 & 1384 & 0.0146 & 0.0231 & 0.033754 \\
M & 731296 & 16.20 & 1628 & 0.0058 & 0.0111 & 0.006456 \\
L & 436310 & 9.66 & 699 & 0.0029 & 0.0080 & 0.002323 \\
VL & 2392818 & 52.99 & 505 & 0.0004 & 0.0011 & 0.000042 \\
Total & 4515417 & 100.00 & 10030 & 0.0097 & 0.0111 & 0.010773 \\
\hline
\end{tabular}

distance equal to the probable maximum runout. The maximum threshold aims to limit the debris flow energy to reasonable values and corresponds to the maximum velocities of debris flow observed in the study area.

\section{Results and discussion}

\subsection{Debris flow hazard initiation map}

A debris flow susceptibility map of five classes (from very high to very low susceptibility) was the starting source of information used in this study. The very high susceptibility class covers $14.5 \%$ of the study area, the high class $6.6 \%$, the medium class covers $16.2 \%$, and the low class represents $9.7 \%$. The remaining $53.0 \%$ is classified as very low or non susceptible area. The spatial probability was calculated using the DF2001 inventory, resulting in spatial probabilities decreasing from the very high to the very low susceptible classes (Table 1).

The susceptibility model used in this study was evaluated using standard evaluation techniques using success rate curve and reaching $89.01 \%$ of area under the curve (Blahut et al., 2010). However, a possible problem arises from the original classification of the susceptibility map, used as the basis for the calculations. Different original classification may certainly lead to changed results in spatial as well as temporal probabilities. However, considering the medium (regional) scale of the analysis, the data available and the Flow-R modelling capabilities, it was decided to keep this assumption.

The temporal probability was calculated from the difference in debris flow activity that was obtained comparing two inventories (DF1981 and DF2001). The DF1981 inventory has 497 scarps covering an area of $3.64 \mathrm{~km}^{2}$. The DF2001 inventory has 573 scarps covering an area of $4.39 \mathrm{~km}^{2}$. In the 20-year period, debris flow activity was observed on 133 scarps, which cover an area of $0.99 \mathrm{~km}^{2}$. Figure 4 shows an example of the difference in debris flow activity within the 20-year period. The temporal probabilities are decreasing in each susceptibility/hazard initiation probability class (Table 1).
The resulting spatial, temporal, and hazard initiation probabilities are summarized in Table 1 and the calculated debris flow hazard initiation map is shown on Fig. 5. For each hazard initiation class a single value of hazard initiation probability is assigned. The very high hazard initiation class has a $0.224783 \times 10^{-4}$ probability of occurrence, which decreases to $0.033754 \times 10^{-4}$ in the high hazard initiation class and to $0.006456 \times 10^{-4}$ in the medium hazard initiation class. The low hazard initiation class has a probability of $0.002323 \times 10^{-4}$, while the very low class reaches hazard initiation probability of $0.000042 \times 10^{-4}$.

The presented approach was performed, because the susceptibility map itself does not have a single value of spatial probability for the entire class. As in the case of the spatial probability value, it was assumed that the temporal probability is constant over the entire hazard initiation probability class. This calculation resulted in five spatiotemporal hazard initiation probability classes for the entire study area. This approach has an assumption in using a single probability value for the entire susceptibility class, which leads to neglecting local controlling factors of debris flow initiation within each susceptibility class. It was decided, however, to assume this condition as the inputs as well as the resulting outputs and the Flow-R model are applied for medium scale analysis. This approach may also lead to the easy application of the methodology to other study areas, where susceptibility maps are already available.

There are also other difficulties and uncertainties connected with the preparation of a debris flow hazard initiation map. Probably the most important uncertainty arises from the temporal probability analysis. As only two temporal datasets are compared, many debris flows source areas could be missing or not recognizable.

Debris flow patterns that were exposed for a long period of time may be partially or totally hidden from view, as it may be after 20 years, due to weather conditions or anthropic interference. It is also possible that new debris flows, that occurred more recently, have obliterated past evidences, so that only the recent ones can be accounted for the analysis. 


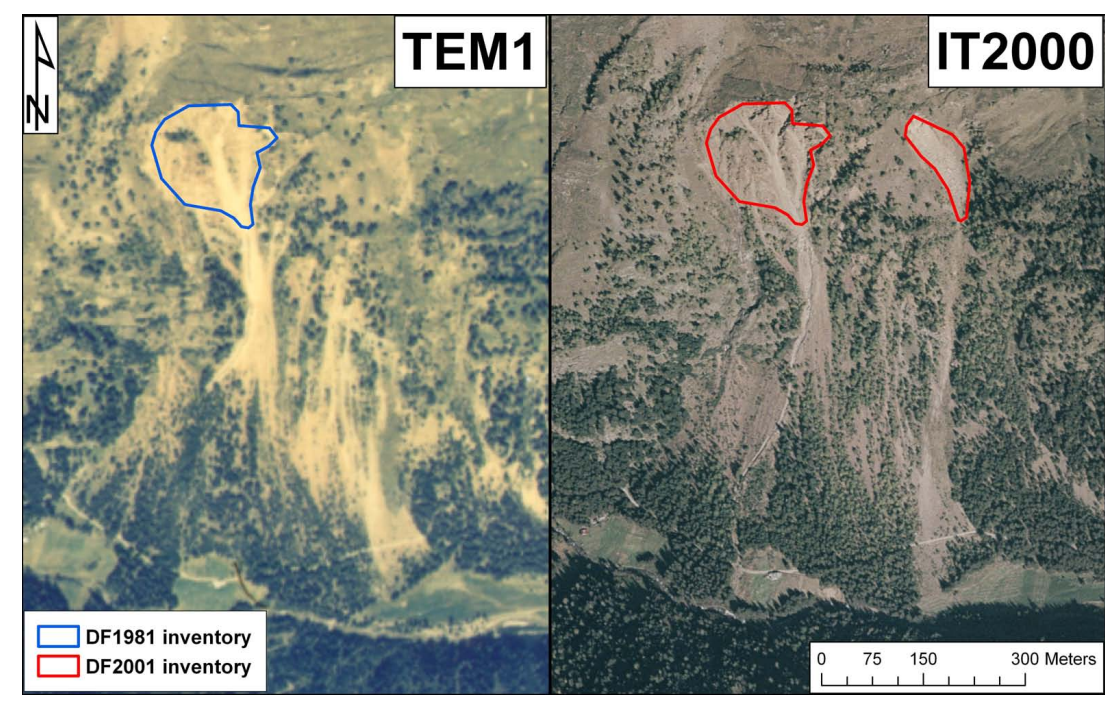

Fig. 4. Example showing the difference between DF1981 and DF2001 inventories, that were used to calculate the temporal probability (frequency) of debris flow initiation. On the left the orthorectified aerial photograph from 1981 (flight TEM1), on the right the orthophoto from 2001 (flight IT2000). Debris flow activity (new scarp) is visible on the photo from 2001, while on the photo taken in 1981 this scarp is missing.

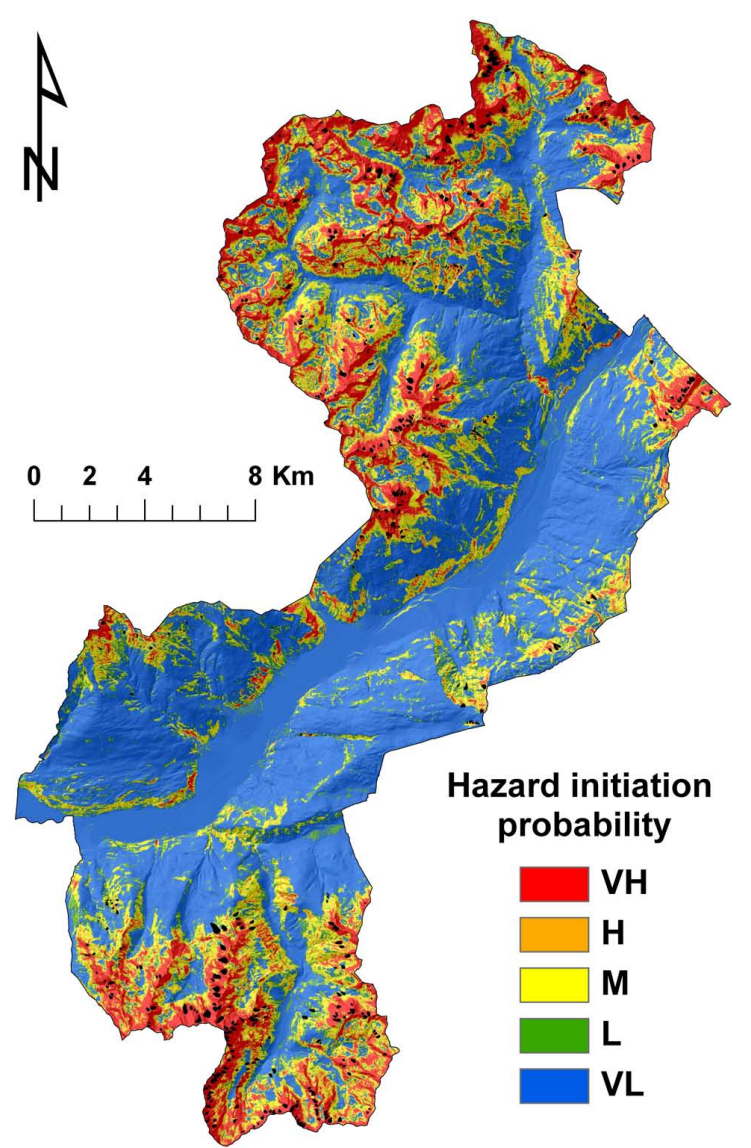

Fig. 5. Debris flow hazard initiation map classified in five classes. VL: very low; L: low; M: medium; H: high; VH: very high. Black dots are the debris flow scarps derived from the DF2001 inventory.
A possible solution to this problem is comparing photosets taken with higher frequency and by longer temporal coverage (e.g. 5 photo sets in 50 years). As a consequence, a lower number of debris flows would be missed and smaller error will be inherent in the temporal probability analysis. Because no other temporal aerial photosets were available at the time of this analysis, these uncertainties were assumed.

It has to be noted, that the temporal probability was calculated mainly to define the hazard areas. If temporal inventories are not available a susceptibility map is sufficient to perform the runout map calculation with Flow-R, when areas more likely to be affected by prospective debris flows can be delimited. This result, however, does not fulfil the hazard definition by estimating the spatial as well as temporal probability of debris flows occurrence.

\subsection{Flow-R modelling}

To produce a source map by the Flow-R model, the hazard initiation probability map was overlaid with thematic layers (slope-flow accumulation relationship, planar curvature map, land use map, geological map) to detect cells with different probabilities, which are most likely to be possible debris flow sources. Four highest hazard initiation classes were used as the input, together with the "extreme fitting" curve and planar curvature map described in Sect. 3.5.1. The land use and geological classes, where debris flow activity was observed were selected by an analysis of the DF1981 and DF2001. The classes with percentage of observed debris flow scarp occurrence are shown in Table 2. No particular difference was observed in the debris flow scarp distribution among geological units. Some differences can be noted from the comparison of the two inventories over the land use classes, 


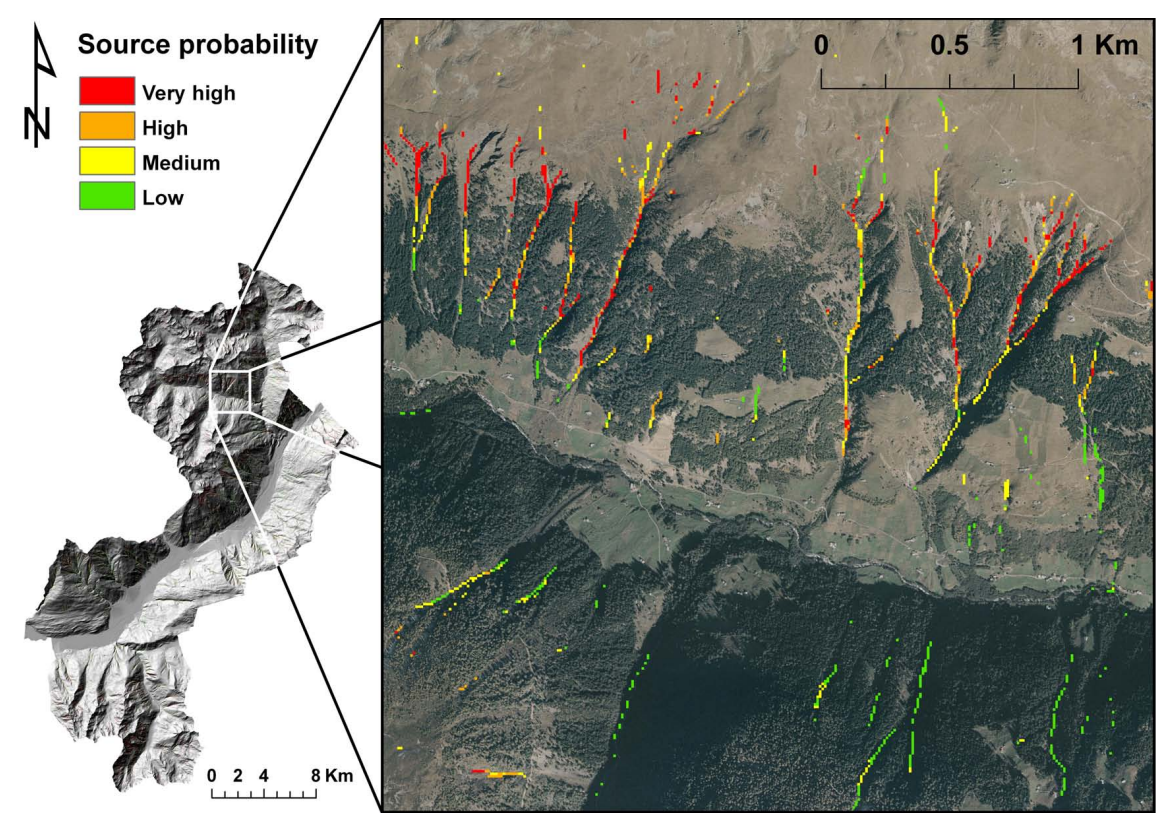

Fig. 6. Example of a source map derived from the Flow-R modelling. Four highest hazard initiation classes together with empirical observations were used to calculate this map.

especially in the bare land, shrubs and bushes and forests. However, this situation can be due to land use changes within the 20-year period, because the land use map used for the evaluation was prepared in 2001. Thus the comparison with the DF1981 inventory does not reflect the land use situation in 1981 .

An example of the resulting debris flow source map with different initiation probabilities is presented in Fig. 6. Sources of the very high class cover an area of $1.31 \mathrm{~km}^{2}$, the high class covers $0.48 \mathrm{~km}^{2}$, the medium class covers $1.08 \mathrm{~km}^{2}$ and low class covers $1.39 \mathrm{~km}^{2}$. On total 42690 cells were identified as possible debris flow sources, covering an area of $4.27 \mathrm{~km}^{2}$. The rest of the study area was not taken into account in the source identification, as it is unlikely that debris flows will be initiated in these zones.

To calibrate the maximum probable debris flow runout, the 19th July 1987 event that affected Tiolo (Grosio municipality) was used. Unfortunately, no other well delimited debris flow data was available for the study area; as a consequence, aerial photographs from 2001 were used to calibrate the possible maximum runout using the edge of alluvial fans where previous debris flows were observed (Fig. 7).

From the calibration phase, the following runout characteristics were selected: maximum runout (shadow) angle $10^{\circ}$; maximum limit velocity of debris flow $15 \mathrm{~m} \mathrm{~s}^{-1}$; and Holmgren exponent of 5 .

Afterwards, a runout map was calculated for the four highest debris flow source classes, resulting in a hazard map A (Fig. 8). The very high hazard class covers $89.2 \mathrm{~km}^{2}$
Table 2. Landuse and geological classes with percentage of observed debris flow occurrence in the DF1981 and DF2001 inventories.

\begin{tabular}{|c|c|c|c|}
\hline & & DF1981 & DF2001 \\
\hline \multirow{5}{*}{ 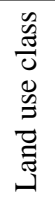 } & Bare land & $69.0 \%$ & $65.5 \%$ \\
\hline & Shrubs and bushes & $5.8 \%$ & $8.5 \%$ \\
\hline & Forests & $4.9 \%$ & $7.2 \%$ \\
\hline & Pastures & $1.0 \%$ & $0.9 \%$ \\
\hline & Vegetation on rocks & $19.2 \%$ & $17.9 \%$ \\
\hline \multirow{7}{*}{$\begin{array}{l}\frac{\tilde{U}}{\tilde{0}} \\
\frac{\tilde{J}}{\tilde{J}} \\
\frac{0}{00} \\
\frac{0}{0} \\
0\end{array}$} & Colluvial sediments & $16.2 \%$ & $17.9 \%$ \\
\hline & Moraine deposits & $7.8 \%$ & $8.0 \%$ \\
\hline & Sedimentary rocks & $8.3 \%$ & $7.2 \%$ \\
\hline & Gneiss & $43.2 \%$ & $40.3 \%$ \\
\hline & Micaschists & $19.0 \%$ & $20.1 \%$ \\
\hline & Intrusive rocks & $3.5 \%$ & $3.6 \%$ \\
\hline & Other rock units & $1.9 \%$ & $2.8 \%$ \\
\hline
\end{tabular}

of the study area and the high hazard class extends over $14.6 \mathrm{~km}^{2}$. Medium and low hazard classes span over $28.3 \mathrm{~km}^{2}$ and $22.3 \mathrm{~km}^{2}$, respectively. The remaining $297.2 \mathrm{~km}^{2}$ of the study area belongs to the very low/residual hazard class. The very high hazard class covers a larger area than the other three hazard classes. The final extent of calculated debris flows paths represents the maximum probable extent not taking into account the volume of the debris mobilized. 


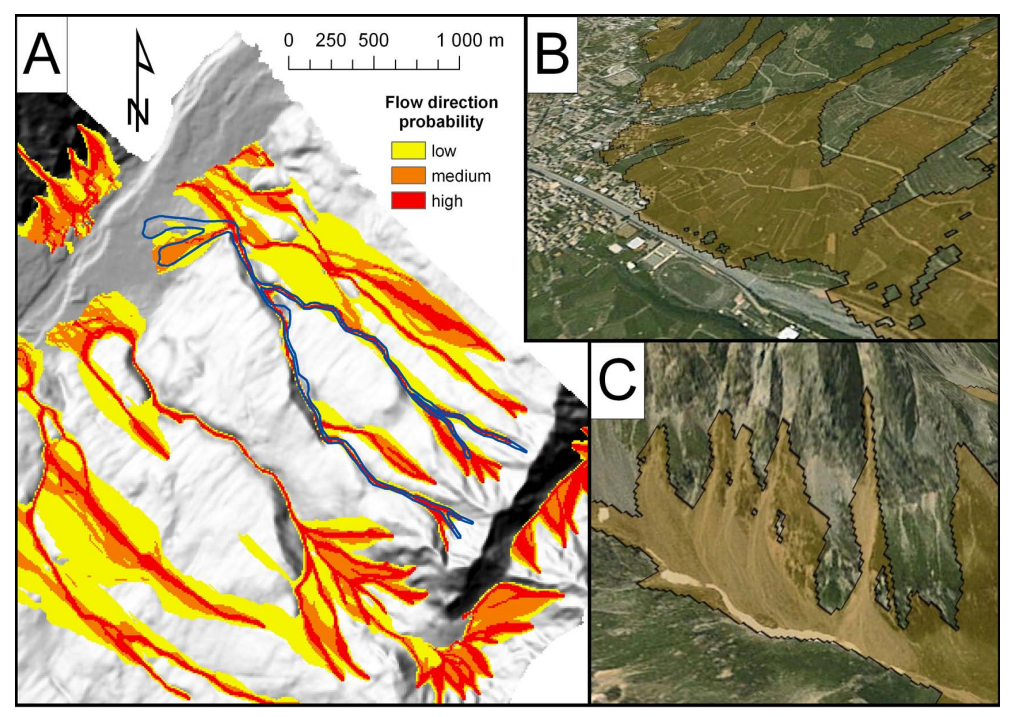

Fig. 7. Examples showing the runout model calibration (yellow polygons). A - debris flow that affected in 1987 Tiolo (Grosio municipality) delimited by the blue polygon (GeoIFFI, 2006); B - 3-D view of the alluvial fan near Tirano with calibrated runout represented as yellow polygon (visualised in Google Earth); C - 3-D view of debris flows in the southern part of the study area with calibrated runout represented as yellow polygon (visualised in Google Earth). See Fig. 1 for location.

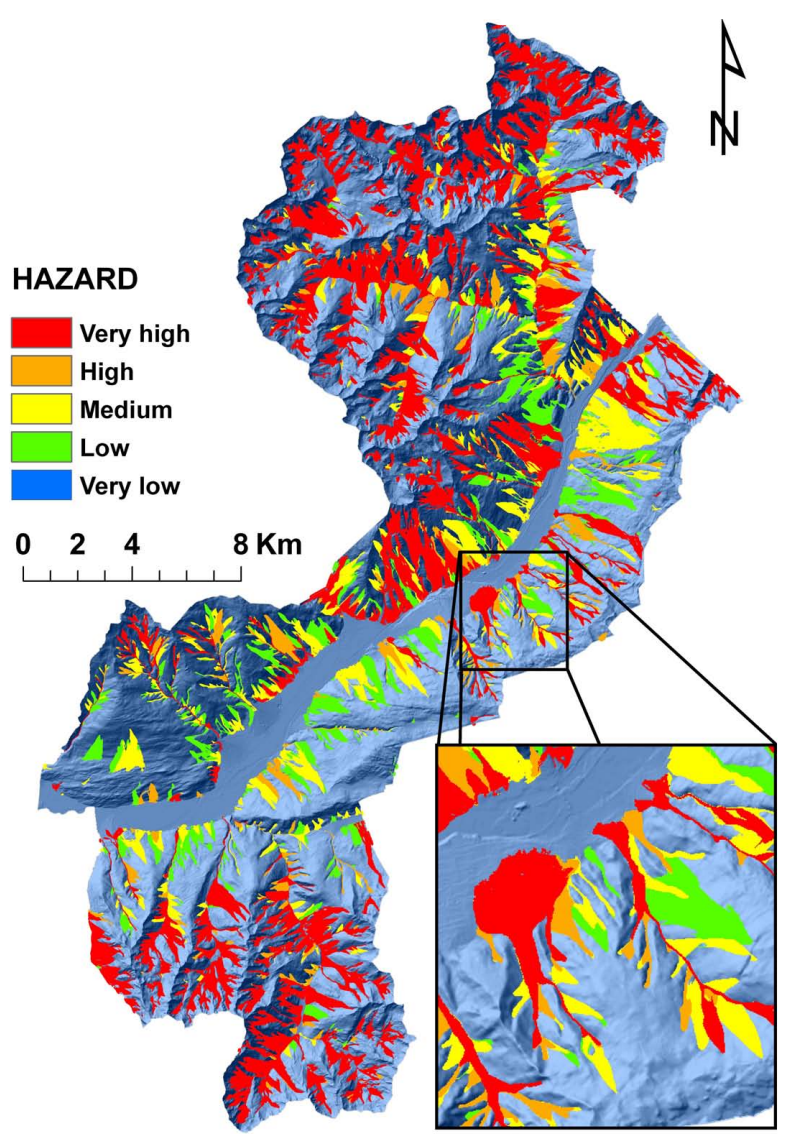

Fig. 8. Final debris flow hazard map A classified in five classes.
Second debris flow hazard map (B) was prepared by subdivision of the hazard classes using the debris flow spreading direction probabilities, because the debris flow magnitude (volume) is impossible to calculate by the Flow-R model. To overcome this problem and to better discriminate the possible different magnitudes (volumes) of debris flows, a qualitative component was added to the hazard map. A reclassification of calculated spreading direction probabilities was made for the four highest hazard classes, using geometric interval classification (Fig. 9). Three sub-classes of spreading direction probabilities were defined in order to have a better idea about different runouts of debris flows with different magnitudes. In each hazard class, the first sub-class (rich colour) shows the area that is the most likely to be affected by a debris flow, while the other sub-classes (light colours) show areas, which are less likely to be affected. As a consequence, these subclasses can be considered as a proxy for the debris flow volume estimation, which is not originally considered in the model calculation. As it was already stated, these spreading direction probabilities are not probabilities in a strict mathematic sense, and they should be interpreted only in a qualitative way.

Major limitations of the Flow- $\mathrm{R}$ model arise in case of misinterpretation of the reality in the DEM; as a consequence, the spreading areas may contain errors. A more precise DEM (e.g. $1-5 \mathrm{~m}$ ) is too heterogeneous for a medium scale analysis and will certainly lead to an increase of computation time. On the other hand a DEM with more than $20 \mathrm{~m}$ resolution may lead to major errors as it is too 


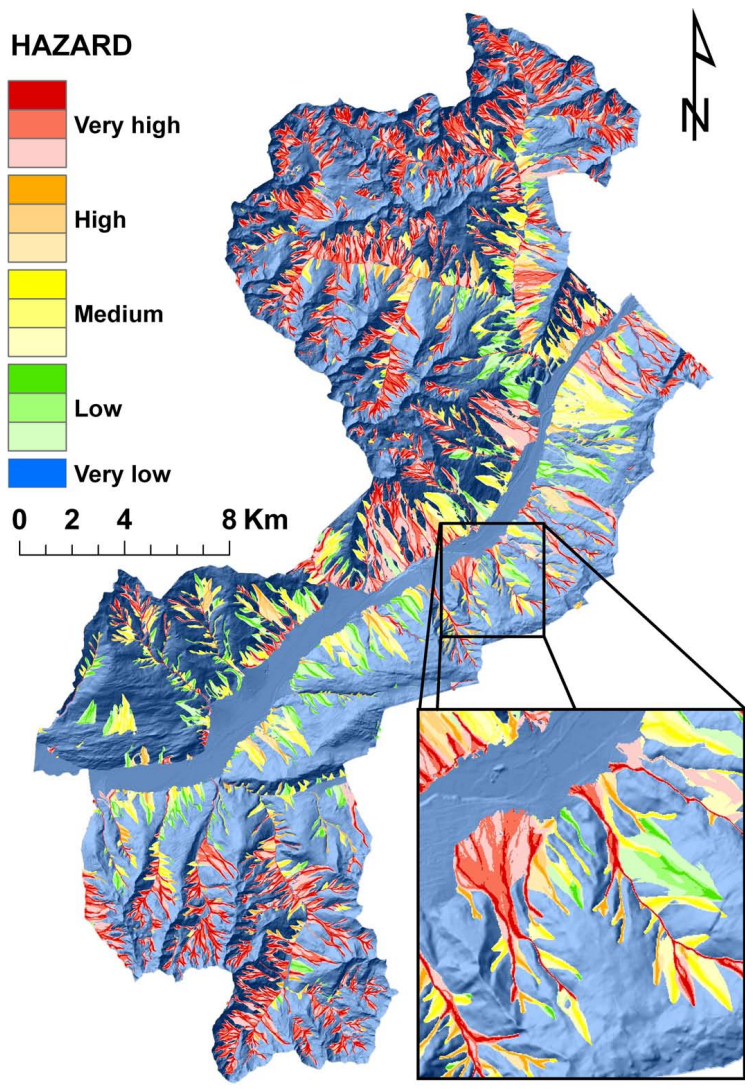

Fig. 9. Debris flow hazard map B showing qualitative information on the runout spreading probabilities. The map is classified in five main hazard classes, each one subdivided in three sub-classes showing the spreading direction probabilities (debris flow volume approximation).

homogenous and some areas of high flow accumulation (gullies) can be missed. The DEM resolution of $10 \mathrm{~m}$ was found appropriate for the medium scale analysis.

\section{Conclusions}

The study showed that the Flow-R model, coupled with a debris flow hazard initiation map and empirical observations, allows fast calculation of debris flow hazard maps. Easy customization and choice of parameters for fast production of debris flow runout maps is the main advantage of the applied methodology. The energy-based algorithm in runout calculation has a physical basis and only a minimum of data is required, as the DEM and debris flow hazard initiation map is the basis of all calculations (source area identification and runout assessment).

It has to be noted, that a medium scale approach has to have some assumptions, which lead to many uncertainties to accomplish the hazard map preparation. First, a reliable susceptibility map has to be available to delimit areas of potential debris flow sources. Afterwards, multi-temporal inventories have to be compared in order to have an idea about the temporal probability/frequency of debris flows. This approach leads to the neglecting of local controlling factors of debris flow initiation. Unlike, for a study on a local/site specific scale, where deterministic modelling and precise calculation of hazard can be performed, not enough information is available on medium scale and more assumptions have to be incorporated.

As in the case of hazard initiation probability estimation, the runout calibration of the Flow-R model does not take into account the local controlling factors of debris flows propagation. Moreover, the multiple flow direction has no physical basis and, since it is a regional model, it does not take into account the debris flow volume. It was shown, however, that the magnitude representation can be approximated by reclassification of the spreading direction probabilities.

It can be concluded that using the presented approach, a medium scale hazard map can be calculated and critical areas can be delimited for a detailed site-specific numerical analysis, where enough data could be obtained with less resources than that for a medium scale analysis. However, for the validation and transferability of the parameters and results to other study areas, more testing is needed.

Acknowledgements. The authors would like to thank Rainer Bell and another anonymous reviewer for their useful comments and suggestions, which improved the quality of the manuscript considerably. We are also grateful to Sami Akbas for corrections in the manuscript. This research was carried out in the framework of the "Mountain risks" project, an EC 6th Framework Project and Marie Curie Research \& Training Network (EC Contract No. MRTN-CT-2006-035798) in which the authors are involved.

Edited by: T. Glade

Reviewed by: R. Bell and another anonymous referee

\section{References}

Blahut, J., van Westen, C. J., and Sterlacchini, S.: Improvement of existing landslide inventory databases for accurate prediction of source areas of landslide-induced debris flows, Geomorphology, 119, 36-51, 2010.

Carrara, A., Cardinali, M., Guzzeti, F., and Reichenbach, P.: GIS technology in mapping landslide hazard, in: Geographical Information Systems in Assessing Natural Hazards, edited by: Carrara, A. and Guzzetti, F., Kluwer, Amsterdam, 135-175, 1994.

CARG project: The New Italian 1:50 000 Geological Map, National Geological Survey, Rome, Italy, 1992.

Chung, Ch.-J. and Fabbri, A.: Probabilistic prediction models for landslide hazard mapping, Photogramm. Eng. Rem. S., 65, 1389-1399, 1999. 
Claessens, L., Heuvelink, G. B. M., Schoorl, J. M., and Veldkamp, A.: DEM resolution effects on shallow landslide hazard and soil redistribution modelling, Earth. Surf. Proc. Land., 30, 461-477, 2005.

Corominas, J. and Moya, J.: A review of assessing landslide frequency for hazard zoning purposes, Eng. Geol., 102(3-4), 193-213, 2008.

Crosta, G. B., Dal Negro, P., and Frattini, P.: Soil slips and debris flows on terraced slopes, Nat. Hazards Earth Syst. Sci., 3, 31-42, doi:10.5194/nhess-3-31-2003, 2003.

Crosta, G. B., Marchetti, M., Guzzetti, F., and Reichenbach, P.: Morphological classification of debris-flow processes in SouthCentral Alps (Italy), in: Proceedings of the 6th International IAEG Congress, Amsterdam, 1565-1572, 1990.

Crozier, M. J. and Glade, T.: Landslide Hazard and Risk: Issues, Concepts and Approach, in: Landslide Hazard and Risk, edited by: Glade, T., Anderson, M., and Crozier, M. J., Wiley \& Sons, Chichester, 1-40, 2005.

DUSAF project: Destinazione d'Uso dei Suoli Agricoli e Forestali, Lombardy Region, Milano, Italy, 2003 (in Italian).

Gamma, P.: dfwalk-Ein Murgang-Simulationsprogramm zur Gefahrenzonierung, Geographisches Institut der Universität Bern, Geographica Bernensia, G66, Verlag des Geogr. Inst. Univ. Bern, Bern, Switzerland, 2000 (in German).

GeoIFFI: The Regional Inventory (1:10.000) of Landslides and Hydrogeological Events, Lombardy Region, Italy, available at: http://ww.cartografia.regione.lombardia.it/GeoIFFI (last access: 16 November 2009), 2006.

Guinau, M., Vilajosana, I., and Vilaplana, J. M.: GIS-based debris flow source and runout susceptibility assessment from DEM data - a case study in NW Nicaragua, Nat. Hazards Earth Syst. Sci., 7, 703-716, doi:10.5194/nhess-7-703-2007, 2007.

Heinimann, H. R.: Methoden zur Analyse und Bewertung von Naturgefahren, Bundesamt für Umwelt, Wald und Landschaft (BUWAL), 1998 (in German).

Holmgren, P.: Multiple flow direction algorithms for runoff modelling in grid based elevation models: An empirical evaluation, Hydrol. Process., 8, 327-334, 1994.
Horton, P., Jaboyedoff, M., and Bardou E.: Debris flow susceptibility mapping at a regional scale, Géorisques IV Geohazards: 4e Conférence canadienne sur les géorisques -4 th Canadian Conference on Geohazards, 20-24 mai 2008 Québec, Canada, 20-24 May 2008.

Huggel, C., Kääb, A., Haeberli, W., and Krummenacher, B.: Regional-scale GIS-models for assessment of hazards from glacier lake outbursts: evaluation and application in the Swiss Alps, Nat. Hazards Earth Syst. Sci., 3, 647-662, doi:10.5194/nhess-3-647-2003, 2003.

Huggel, C., Kääb, A., Haeberli, W., Teysseire, P., and Paul, F.: Remote sensing based assessment of hazards from glacier lake outbursts: a case study in the Swiss Alps, Can. Geotech. J., 39, 316-330, 2002.

ITC: ILWIS - Remote Sensing and GIS software: Integrated Land and Water Information System, available at: http://www.itc.nl/Pub/Home/Research/Research_output/

ILWIS_Remote_Sensing_and_GIS_software.html (last access: 15 July 2009), 2009.

Michael-Leiba, M., Baynes, F., Scott, G., and Granger, K.: Regional Landslide Risk to the Cairns Community, Nat. Hazards, 30, 233-249, 2003.

Quinn, P., Beven, K., Chevallier, P., and Planchon, O.: The prediction of hillslope flow paths for distributed hydrological modelling using digital terrain models, Hydrol. Process., 5, 5979, 1991.

Rickenmann, D. and Zimmermann, M.: The 1987 debris flows in Switzerland: documentation and analysis, Geomorphology, 8, 175-189, 1993.

Takahashi, T.: Estimation of potential debris flows and their hazardous zones: Soft countermeasures for a disaster, Natural Disaster Science, 3, 57-89, 1981.

van Westen, C. J., van Asch, T. W. J., and Soeters, R.: Landslide hazard and risk zonation: why is it still so difficult?, B. Eng. Geol. Environ., 65, 176-184, 2005.

Varnes, D. J.: Landslide hazard zonation: A review of principles and practice, Paris, UNESCO, 1984. 